MUSICA THEORICA 201902

SCIENTIFIC ARTICLE

Data do recebimento: 21/05/2019

Data da aprovação final: 26/06/2019

\title{
A Visita de Beethoven ao carnaval brasileiro em 2017: Ensaio sobre fantasia analítica e hermenêutica narrativa em música ${ }^{1}$
}

\author{
Beethoven's Visit to Brazil During the 2017 Carnival: Essay on Analytical \\ Fantasy and Narrative Hermeneutics in Music
}

\author{
Ilza Nogueira \\ Universidade Federal da Paraíba \\ Academia Brasileira de Música
}

Resumo: $O$ presente trabalho apresenta uma proposta narrativa para a cognição musical da Chacona ao Luar do compositor brasileiro Edino Krieger (Brusque, SC, 1928), uma peça para piano solo composta em 2017. Motivada por uma encomenda da pianista alemã Susanne Kessel, a Chacona integra o projeto internacional "250 Peças para Beethoven", uma gigantesca homenagem antecipada ao compositor alemão pelos vindouros 250 anos de seu nascimento. Segundo o referido projeto, os compositores convidados deveriam criar peças que remetessem à obra de Beethoven. Assim o fez Krieger em sua Chacona, cujo título não deixa dúvidas sobre o cumprimento da exigência. Objetivando a observação da obra enquanto discurso musical potencialmente significativo, este estudo analítico investiga a estrutura formal, os materiais musicais e as técnicas composicionais, no sentido da construção de um argumento que justifique a obra enquanto homenagem musical contextualizada tanto histórica quanto culturalmente. Recursos composicionais intertextuais e interculturais interagindo num plano de inter-historicidade foram fundamentais à percepção de uma semântica musical e estratégicos para o reconhecimento de "agenciamento" e "atorialidade", ou seja, a identificação da atuação de agentes musicais e do papel funcional dessa atuação numa trajetória narrativa. No âmbito teórico, argumentações sobre a narratividade musical derivadas de Byron Almén (2003), aliadas a alguns conceitos da psicanálise freudiana e da teoria lacaniana (notadamente o trinômio "Imaginário", "Simbólico" e "Real") esteiam a argumentação narrativa que se define a partir da escritura musical. Tendo em vista que os aspectos imaginativos da mente na interpretação performática e na escuta submetem a realidade do texto musical a uma re-subjetivação, esta interpretação narrativa propõe-se aberta, ambígua e questionável.

\footnotetext{
${ }^{1}$ Trabalho apresentado no evento "Música Analítica 2019: Simpósio Internacional em Análise e Teoria da Música", ocorrido na Universidade Católica Portuguesa, Campus da Foz, Cidade do Porto, entre 21 e 23 de março de 2019.
} 
Palavras-chave: Música e narratividade; Análise musical interdisciplinar; Música e psicanálise; Homenagem musical; Edino Krieger

Abstract: This paper proposes a narrative analytical approach for Edino Krieger's Mondschein Chaconne, a piano piece composed during the Brazilian carnival season of 2017. Commissioned by German pianist Susanne Kessel, Krieger's chaconne integrates the international project "250 Pieces for Beethoven", an anticipated tribute to the German composer's forthcoming 250th birthday. Considering the potentially meaningful discourse of this music, the analysis observes the formal structure, music materials and compositional techniques in the sense of composing an argument that justifies the chaconne as a historically and culturally contextualized musical tribute. Intertextual and intercultural resources interacting in a level of inter-historicity have been crucial for the recognition of musical semantics and considered strategic to the acknowledgement of musical 'agency' and 'actoriality', namely, the identification of acting musical agents and their functional role in a narrative trajectory. In the theoretical perspective, studies on musical narrativity by Byron Almén associated with concepts from the Freudian psychoanalysis and the Lacanian theory (notably the trinomial "Imaginary", "Simbolic" and "Real") support the narrative plot outlined from the score. Considering that the mind's imaginative aspects in music performance and listening submit the reality of the score to resubjectivations, this narrative proposal ultimately reveals itself as an open, ambiguous and questionable interpretation.

Keywords: Musical narrativity; Interdisciplinary music analysis; Musical tribute; Edino Krieger

\section{Introdução}

Em 2020 o mundo musical celebrará 250 anos do nascimento de Beethoven, o "gênio indomado", um mito aberto a múltiplas tentativas de decifragem. Comemorações já se antecipam, como é o caso do projeto internacional "250 Piano Pieces for Beethoven" da pianista alemã Susanne Kessel. Compositores de todo o mundo foram convidados por ela a "dialogarem" com o ilustre homenageado através da linguagem da música. Concebido em 2015, esse grandioso tributo vem resultando numa multiplicidade de leituras interpretativas da personalidade musical de Beethoven, as quais se expressam como uma notável variedade de diálogos inter-históricos, interculturais e

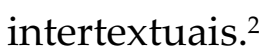

Edino Krieger (Brusque, SC - 1928) foi o compositor brasileiro convidado a fazer parte desse grande "fórum musical" sobre Beethoven. Sua "Chacona ao

\footnotetext{
${ }^{2}$ As 250 obras que integram este projeto serão publicadas em 2020 pela editora Musica Ferrum (Londres, UK). Gravações para transmissão radiofônica e CDs estão sendo realizadas pela WDR (Colônia, Alemanha) desde 2016.
} 
MUSICA THEORICA Revista da Associação Brasileira de Teoria e Análise Musical 2019, v. 4, n. 1, p. 11-29 - Journal of the Brazilian Society for Music Theory and Analysis@ TeMA 2019 - ISSN 2525-5541

Luar" (Mondschein Chaconne em alemão) foi composta no apogeu do carnaval de 2017. O espírito carnavalesco lúdico, alegre e extrovertido motivou a homenagem brasileira ao mal-humorado, taciturno e recluso compositor alemão. ${ }^{3}$ Meu estudo objetiva revelar um possível significado derivado dessa correlação paradoxal na chacona de Krieger.

Antes de adentrar o estudo analítico propriamente dito, algumas considerações sobre recursos estruturais significantes ao discurso narrativo são oportunas à compreensão da escolha do ponto de vista da narratividade musical para este ensaio.

\section{Considerações teóricas}

Um dos recursos estruturais mais valorizados na construção de narrativas é a redundância. Segundo o crítico literário norte-americano Peter Brooks, a repetição é inerente ao discurso narrativo, dando forma à energia, estabelecendo conexões e proporcionando compreensão. A narrativa, diz Brooks, "deve fazer uso perceptível de repetições específicas para criar a trama, ou seja, para nos mostrar uma interconexão significante dos eventos"4 (Brooks 1984, p. 99).

A distinção entre a "repetição pura" e a "repetição diferente" é significativa para a compreensão do poder semiótico da repetição. A diferença na redundância de um evento leva a uma compreensão dos episódios contíguos como um sistema mutualista, funcionando como numa "cadeia significante". ${ }^{5}$

Em seu artigo "Freud and the Semiotics of Repetition", Robert Rogers ${ }^{6}$ atenta para o valor semiótico do conceito freudiano da "compulsão à repetição":

[...] repetição é significado. Repetição é sempre significativa. O verdadeiro significado do que Freud chama compulsão à repetição está [...] no poder de seus aspectos significantes: sua força como significado e não seu significado

\footnotetext{
${ }^{3}$ A estreia da Chacona, ocorrida a 22.5.2017 (Bonn, Haus der Luft- und Raumfahrt), encontra-se disponibilizada na internet em: https://vimeo.com/219808597.

${ }^{4}$ [Narrative] must make use of specific, perceptible repetition in order to create plot, that is to show us a significant interconnection of events.

${ }^{5}$ A teoria psicanalítica de Lacan define a expressão "cadeia significante" como uma combinação associativa de significantes, provocando uma reação em cadeia. Uma explicação do conceito particularizada na análise da Chacona de Krieger se encontra na Nota 15.

${ }^{6}$ Robert Rogers, professor na Universidade Estadual de New York em Buffalo, é reconhecido pela sua produção em crítica literária psicanalítica.
} 
como força. Considerada como significação, [...] repetição é re-apresentação e re-apresentação é representação (Rogers 1987, p. 584). ${ }^{7}$

A estrutura da Chacona, em sua trajetória cíclica, repetitiva e variante, estimula a percepção de narratividade na peça de Krieger. Ademais, enquanto o processo da variação contínua se desenvolve, a estrutura de larga escala da peça se refere a um outro modelo cíclico: a simetria palindrômica ABA. ${ }^{9}$

Outro recurso igualmente valorizado na construção de narrativas é a intertextualidade. A emergência da memória de vivências musicais em dialogia com novas experiências é um expediente estratégico para a compreensão da "atorialidade" e do "agenciamento",10 caraterísticas discursivas essenciais à narrativa. A "voz" do outro propicia o reconhecimento de diálogos; diálogos pressupõem personagens (atorialidade); personagens implicam ações (agenciamento); personagens e ações resultam em tramas.

É de Byron Almén, um dos teoristas expoentes em narratologia musical, o entendimento definitivo sobre a essência da cognição narrativa em música. Segundo ele, "a narrativa musical é o processo através do qual o ouvinte percebe e segue uma transvaloração de relações hierárquicas culturalmente significativa numa determinada temporalidade" (Almén 2003, p. 12). ${ }^{11}$

\footnotetext{
${ }^{7}[\ldots]$ repetition is meaning. Repetition is always meaningful. The true significance of what Freud calls the repetition-compulsion lies in the actual power of its signifying aspects: its force as meaning, not its meaning as force. Considered as signification, repetition is always [...] representation and re-presentation is always representation (Rogers 1987, p. 584).

${ }^{8}$ A Chacona de Krieger corresponde ao conceito que mais se reconhece como passacaglia: a forma variação-ostinato baseada numa linha melódica fundamental (ground).

${ }^{9} \mathrm{O}$ modelo ABA corresponde a uma das 3 categorias da sintaxe agencial definidas por Greimas: aquela que se define na relação de mutualidade binária do tipo "Sujeito - Objeto", na qual "A deseja B, e onde a relação transitiva ou teleológica é o desejo" (Apud Grabócz \& McClelland 1999, p. 20). Interpretando a sequência sintática sob o ponto de vista da semântica, A corresponde a uma ordem inicial transgredida em B e restaurada em A.

${ }^{10}$ Os termos "agenciamento" e "atorialidade" implicam, respectivamente, no reconhecimento da atuação de "agentes musicais" (unidades sintáticas antropomorfizadas na cognição de uma trajetória narrativa) e do papel funcional dessa atuação numa possível trama.

${ }^{11}$ Drawing on Liszka, I define and situate musical narrative as follows: Musical narrative is the process through which the listener perceives and tracks a culturally significant transvaluation of hierarchical relationships within a temporal span (Almén 2003, p. 12).
} 
Transvaloração cultural, intertextualidade e redundância: são estes os três conceitos que subsidiam minha interpretação narrativa da Chacona de Krieger, no sentido da compreensão do caráter referencial e representativo desta obra.

\section{Fantasia analítica}

Minha interpretação da Chacona ao Luar considera Beethoven como personagem de uma suposta e possível narrativa que se define a partir da memória historiográfica acerca da personagem bem como do contexto cultural de onde provém o narrador: Edino Krieger, músico brasileiro de ascendência teuto-italiana.

A peça inicia com a "voz" de Beethoven (Ex. 1). O reconhecimento da frase "magnética" do primeiro movimento da Sonata op. 27 n. 2, da forma como se apresenta desde a anacruse ao compasso 1 até o compasso 4 - uma citação melódica, filtrada do contexto harmônico-textural original e sem algum novo tratamento composicional -, funciona como um retrato, uma ilustração de capa de livro biográfico.

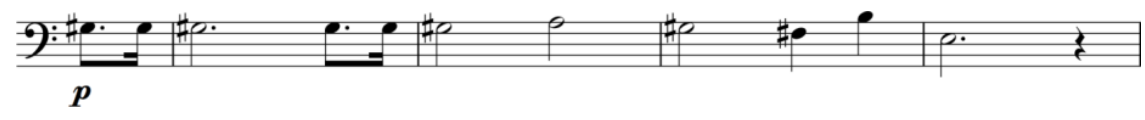

Exemplo 1: Chacona ao Luar, c. 1-4

Após a breve introdução de Beethoven, a composição de Krieger inicia com um contraponto a 3 vozes (Ex. 2), apresentando concepções independentes relativas ao que deverá executar a mão esquerda - um "comportado" e tradicional contraponto ao "cantus firmus" beethoveniano - e a mão direita uma fluente e lírica melodia de contorno ondulante, onde podemos reconhecer uma alusão ao ostinato rítmico que sublinha a condução melódica em todo o primeiro movimento da Sonata de Beethoven (Ex. 3). 


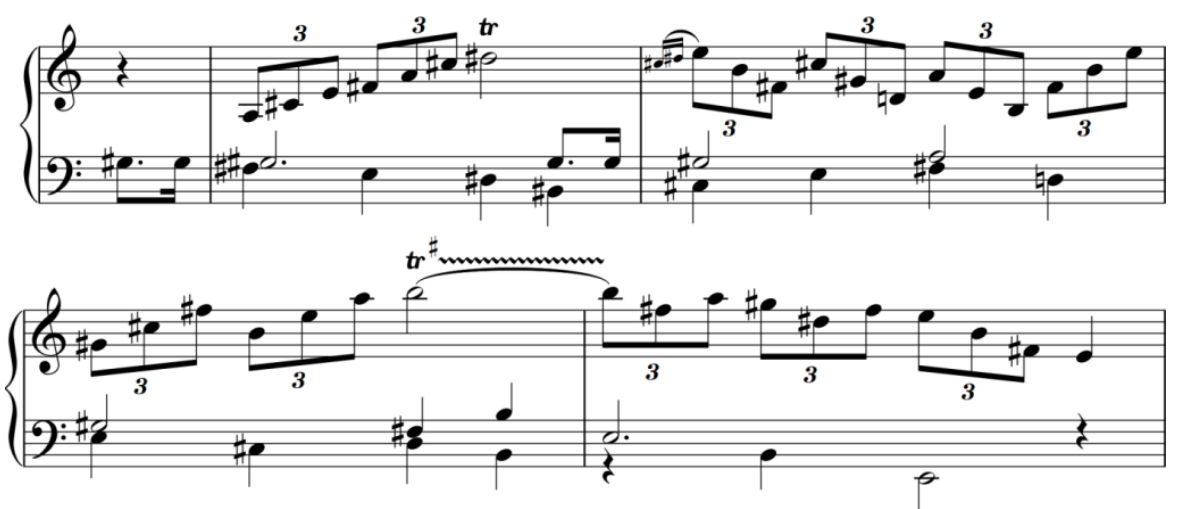

Exemplo 2: Chacona ao Luar, c. 4.4-8

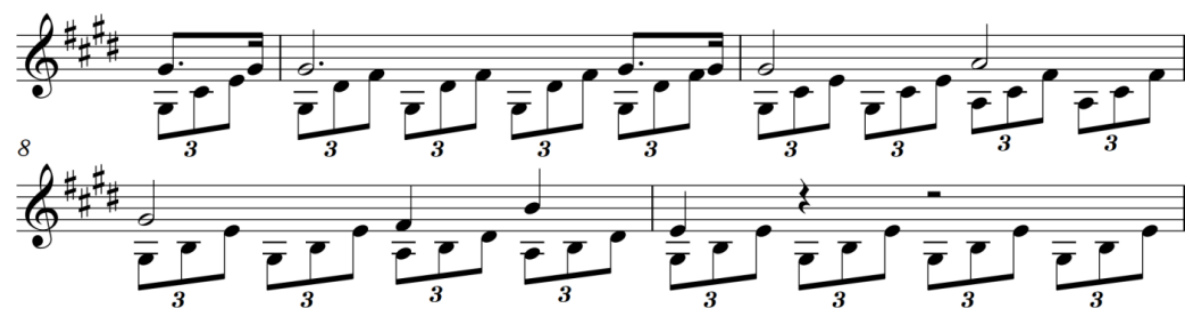

Exemplo 3: Beethoven, Sonata op. 27 n. 2, 1ํㅡㄹ movimento, c. 6-9

Neste primeiro enunciado ${ }^{12}$ (Ex. 2), nota-se, portanto, uma recaracterização do Ur-text, realizada com a inversão das funcionalidades de seus elementos: a melodia original se tornou em Krieger a base estrutural; e o acompanhamento harmônico em tríades arpejadas repetidas reinventou-se na superfície melódica, onde a profusão de ondulações se traduz em exuberante e luminoso lirismo. De início, portanto, a Chacona se mostra como recriação da sua referência musical. Em minha interpretação narrativa, a primeira frase de Krieger funciona como uma apresentação da personagem Beethoven, evidenciando a personalidade artística ambígua, cuja produção concilia aspectos da tradição culta aprendida com a invenção.

A divisa com a variante seguinte (Ex. 4) dá-se pela mudança brusca de centro tonal entre Dó\# menor e Dó Maior, correspondendo ao que ocorre no movimento da sonata de Beethoven. Nessa segunda variante, o contraponto da mão esquerda permanece inalterado em seu estilo, enquanto a insinuante linha

\footnotetext{
${ }^{12}$ Enunciados são unidades discursivas mediadoras de significados. Sendo o objetivo desta análise o reconhecimento de um discurso narrativo, optei pelo termo "enunciado" em detrimento de "frase" (mais adequado a uma análise da sintaxe da obra).
} 
MUSICA THEORICA Revista da Associação Brasileira de Teoria e Análise Musical 2019, v. 4, n. 1, p. 11-29 - Journal of the Brazilian Society for Music Theory and Analysis@ TeMA 2019 - ISSN 2525-5541

melódica da mão direita ganha ímpeto (com as semicolcheias), complexidade (na longa ascendência cromática do compasso 11) e densidade (na transformação do caráter melódico em progressão acórdica). Se considerarmos a melodia da mão direita como signo da livre invenção, podemos dizer que o lado inventivo da personagem "ganhou asas". Na finalização da frase, o progressivo distanciamento das mãos direita e esquerda, em igualmente progressivo aumento de intensidade sonora, sugere a evolução do diálogo entre tradição e invenção a um clímax. Nessa evolução, quando as divergências entre mão direita e mão esquerda se conciliam, percebe-se um ganho em dramaticidade até a grandiloquente chegada à tônica (Dó), projetada em 4 oitavas.
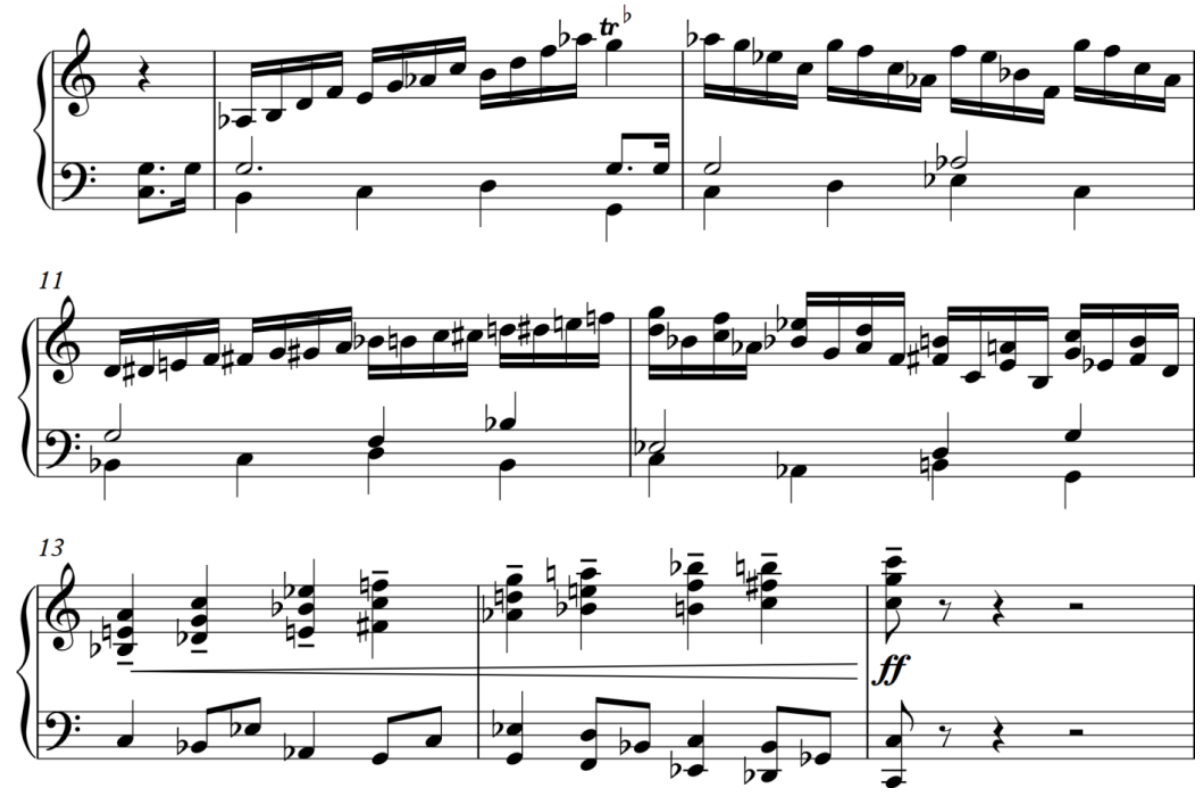

Exemplo 4: Chacona ao Luar, c. 8.4-15.1

O trecho sequente (Ex. 5) se configura como um platô alcançado pela progressão antecedente (c. 13.1-15.1), climatizando a crescente energia com a figuração de fusas. Na interação entre as mãos esquerda e direita, a evolução rítmica se refere à célula pontuada da frase apropriada de Beethoven (mão esquerda), assim como também alude a um dos padrões rítmicos básicos da roda de samba (mãos esquerda e direita). ${ }^{13} \mathrm{~A}$ percepção desta interculturalidade deve por a intuição analítica em "modo de espera".

\footnotetext{
${ }^{13}$ Normalmente executado no pandeiro, o padrão rítmico alterna, sucessivamente, a batida do polegar na borda do instrumento (1a e 4a semicolcheias no registro mais grave) e o toque com as pontas dos dedos e depois com o pulso no centro da pele (2a e à 3a semicolcheias no registro mais
} 

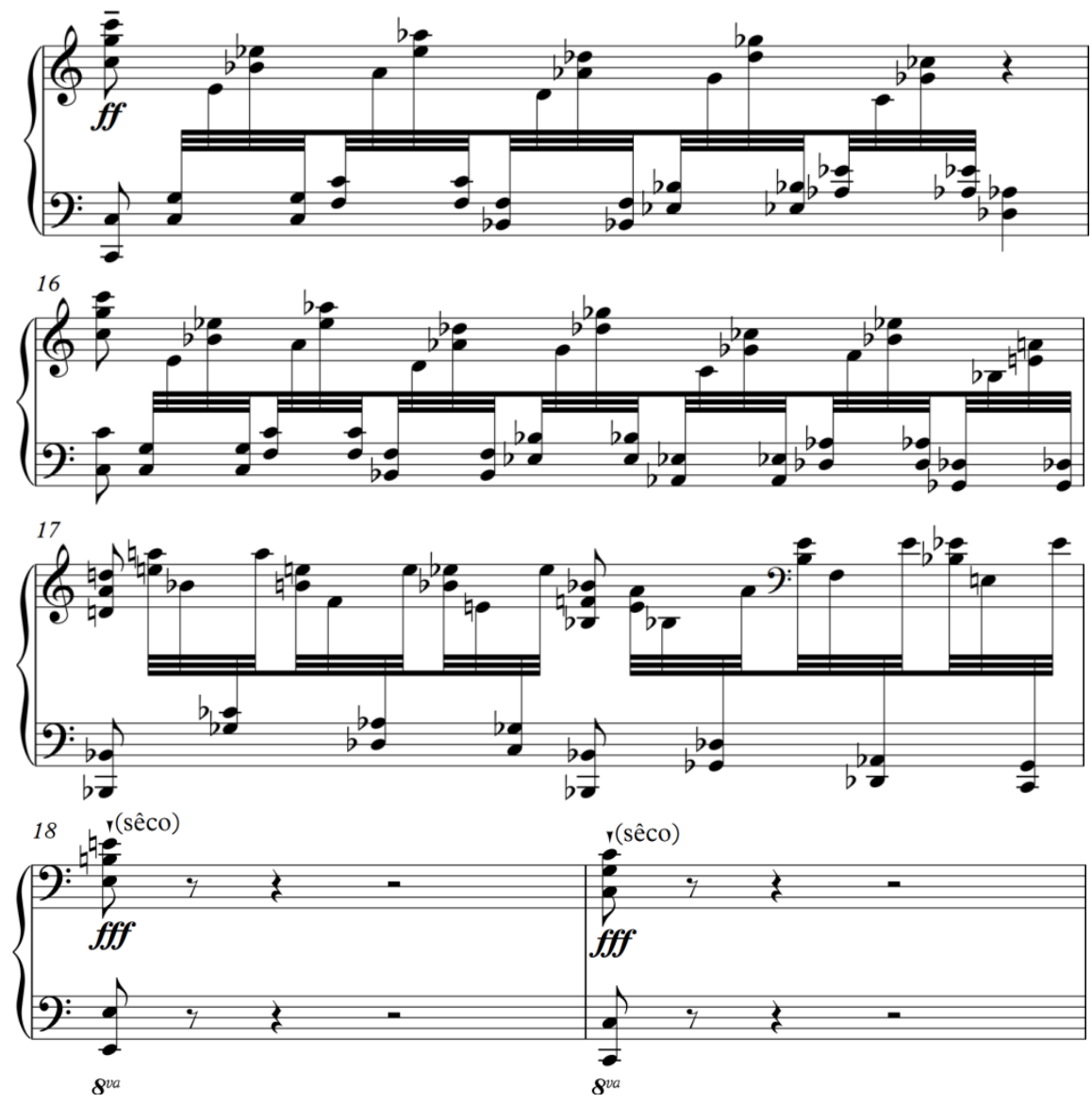

Exemplo 5: Chacona ao Luar, c. 15-19

O expressivo lirismo inicial se transfigurou radicalmente com a troca da polifonia por uma densa homofonia, com a progressiva ampliação da tessitura e da intensidade, e, principalmente, com a transformação da natureza mélica e cantabile no caráter rítmico enérgico e percussivo.

agudo). Devo a percepção dessa referência cultural, importante à minha interpretação narrativa, à pianista brasileira Cristina Capparelli Gerling. Sua execução deste trecho (c. 15-18) difere radicalmente da virtuosística e dramática execução da pianista alemã Susanne Kessel, que o executa com maior velocidade, enquanto o uso do pedal de sustentação dilui a percepção da implícita brasilidade rítmica. Sem uso do pedal ou implementação de andamento, Gerling imprime ao trecho uma feição jocosa, insinuando uma movimentação intercultural do início ao final desta primeira seção da Chacona. O fato me faz lembrar algumas considerações de Byron Almén sobre características influentes na cognição narrativa, salientando que o condicionamento cultural da performance permite ou convida o ouvinte a estar atento a determinados requisitos da compreensão narrativa da música (v. Almén 2003, p. 8). Faz-me também lembrar Marcos Nogueira em seu texto "Dimensões da produção imaginativa musical: movimentos, formas e intenções". Discutindo distintas vertentes do processo cognitivo, Nogueira ressalta a "cognição situada ou incorporada": uma vertente mais recente das ciências cognitivas, que entende a realidade como algo dependente do seu observador, da sua dinâmica interativa do estar-nomundo (Nogueira 2019, p. 20, nota 4). 
MUSICA THEORICA Revista da Associação Brasileira de Teoria e Análise Musical 2019, v. 4, n. 1, p. 11-29 - Journal of the Brazilian Society for Music Theory and Analysis @ TeMA 2019 - ISSN 2525-5541

Mais do que a ambiguidade estética e a repetição variada, a progressiva transfiguração do lírico ao dramático caracteriza a narratividade desta primeira seção estrutural da peça (vamos chama-la de Seção A). Narratividade esta que estimula as seguintes hipóteses interpretativas:

1. A Seção A se refere à apresentação de uma personagem musical ambígua, situada entre dois mundos estéticos;

2. Esta personagem diz respeito ao gênio de Bonn, como o conhecemos historicamente, com um pé no classicismo e outro no romantismo;

3. A progressiva mutação do plácido, lírico e comedido ao agitado, dramático e soberbo pode representar a evolução da personalidade de Beethoven, dos anos de jovem aprendiz aos de um artista maduro, pressionado por dramas pessoais;

4. A enérgica interseção cultural na passagem entre os compassos 15 a 17 estaria representando um excitante processo de embate inconsciente $^{14}$ entre o mundo interior da personagem (realidade) e estímulos que afluem de um universo externo (fantasia), provocando uma espécie de catexia;

5. A dramática irrupção do silêncio nos compassos 18 a 19 pode representar uma anticatexia (a emergência do ego, reprimindo a energia irracional do id);

6. Do ponto de vista de uma versão historiográfica, a enérgica dramaticidade desenvolvida no trecho entre os compassos 15 a 19 poderia referir-se ao drama pessoal de Beethoven - a progressiva perda de audição - manifesto no trágico “Testamento de Heiligenstadt" escrito em 1802 (pouco depois que compôs a Sonata ao Luar).

Se todas estas conjecturas parecerem razoáveis, somente um exame da música posterior, sob o ponto de vista da configuração de uma "cadeia significante", ${ }^{15}$ responderá favoravelmente (ou não) à sua legitimidade.

\footnotetext{
${ }^{14}$ A adjetivação "inconsciente" se justifica pelo razoável obscurantismo da interconexão motívica na passagem (a célula pontuada derivada de Beethoven e o padrão rítmico do samba).

${ }^{15}$ A expressão "cadeia significante" é utilizada no sentido da compreensão de uma necessária remissão sígnica entre os enunciados musicais (metaforicamente compreendidos) para que uma lógica significante se estabeleça durante a escuta da peça (um raciocínio narrativo).
} 
Após a conclusão dramática da Seção A (Ex. 5, c. 18-19), a citação de Beethoven é retomada numa distinta concepção estética (Ex. 6).
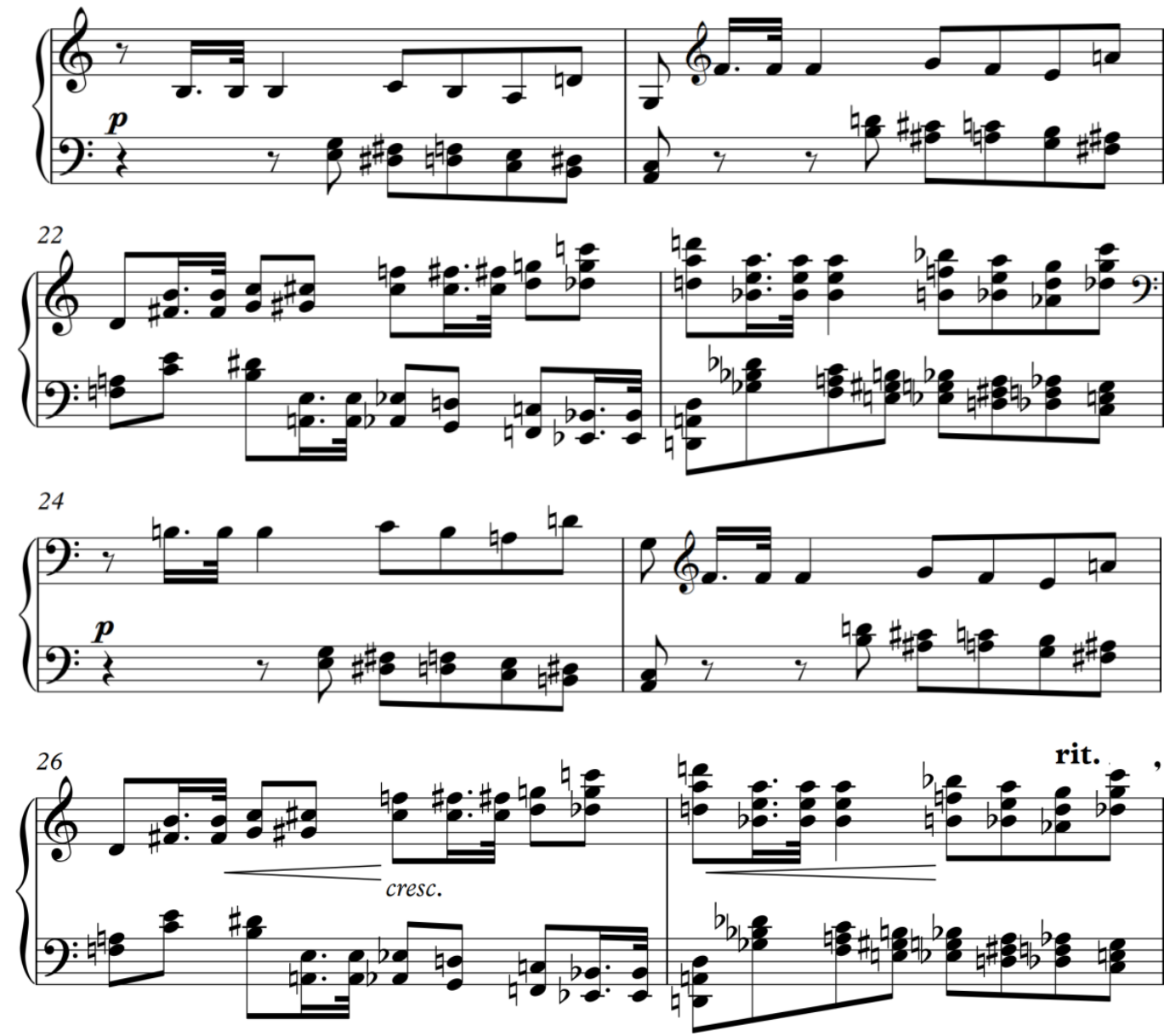

Exemplo 6: Chacona ao Luar, c. 20-27

A languidez das mínimas foi substituída pela marcha apressada das semínimas; assomam-se transposições fugazes, acompanhadas por sequências cromáticas; fragmentações em imitações sequentes se avultam em intensidade, percorrendo direções contrárias. A ascensão na tessitura e a progressiva densidade sonora assinalam para uma conclusão frustrada no compasso 24 . A pequena ruptura e o recomeço da frase prometem novamente - e mais enfaticamente - a conclusão outra vez interrompida pelo início de uma nova variante (vide Ex. 7, c. 28) no processo das variações contínuas. Diferentemente da seção anterior, onde se reconhece um caráter expositivo, este trecho tem características de uma passagem transitiva. Do ponto de vista narrativo, insinuase uma situação de ansiedade, esforço e busca que pode traduzir-se como angústia, ou desejo. 
MUSICA THEORICA Revista da Associação Brasileira de Teoria e Análise Musical 2019, v. 4, n. 1, p. 11-29 - Journal of the Brazilian Society for Music Theory and Analysis @ TeMA 2019 - ISSN 2525-5541

Pergunto: Seria razoável imaginar um vínculo narrativo entre o clímax final da seção anterior e estes oito compassos consecutivos? Poderíamos considerar a transformação da melodia mítica e a perda da eloquência na nova caracterização musical como um processo excitatório da personalidade criativa antevendo um mundo sonoro adiante do seu, em angustiante e desejosa busca da invenção? Poderíamos interpretar esta passagem como uma pulsão direcionada a um vislumbrado objeto de desejo? Poderia esta pulsão ser consequente da ambiguidade cultural insinuada no final da Seção A? A observação da continuidade da música certamente fornecerá subsídios para possíveis respostas.

No compasso 28, a indicação Più mosso, cantabile sinaliza o início da Seção $\mathrm{B}$, correspondendo à exposição de uma ideia de caráter lírico e contorno ondulante em Dó menor (Ex. 7). Os valores estéticos que fundamentaram a composição até então - típicos da tradição culta da Europa central - perdem sua preponderância para traços estéticos emblemáticos da Gestalt vernácula brasileira: o ritmo sincopado, a irregularidade métrica e a ondulação melódica.

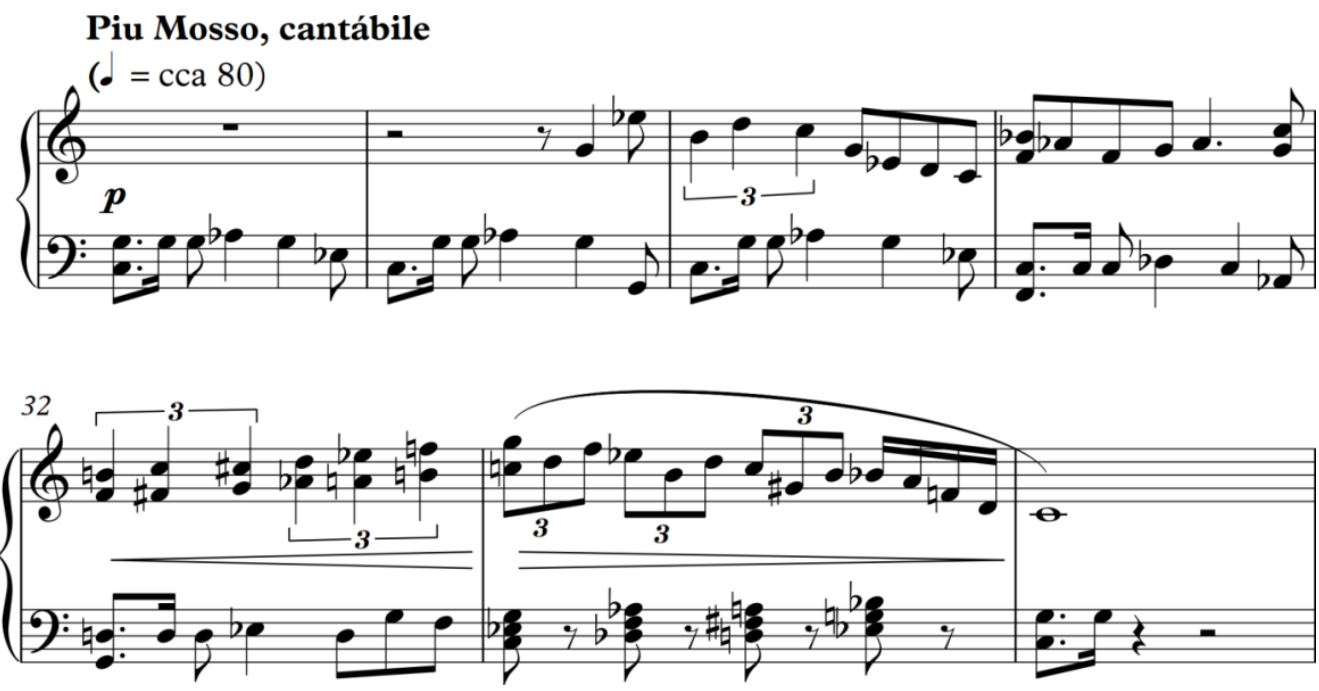

Exemplo 7: Chacona ao Luar, c. 28-34

O referente germânico oitocentista transgride a simetria rítmica característica da sua cultura para adaptar-se à assimetria dos ritmos étnicos afrobrasileiros. ${ }^{16}$ Essa versão "teuto-brasileira" da matriz de Beethoven interage com

\footnotetext{
${ }^{16}$ A estilização da citação de Beethoven poderia ser interpretada como ironia: uma versão do "sublime" em âmbito do "vulgar", do "jargão", do "dialeto", procedimento típico do que, na Teoria da Literatura, se reconhece como "carnavalização": a aproximação entre valores opostos
} 
uma melodia lírica e ondulante, cujo gestual cantabile é típico da brasilidade musical vernácula. ${ }^{17}$ Ademais, essa melodia apresenta características de contorno intervalar análogas às da marcha-rancho "As Pastorinhas" (1937) (Exs. 8a e 8b). A analogia com a canção carnavalesca é outro recurso intertextual significativo na peça. Se a latente brasilidade rítmica nos compassos 15 a 18 pode ser considerada um processo inconsciente, aqui a sua materialização na alusão à canção carnavalesca adquire o status de uma expressão ao nível da consciência.

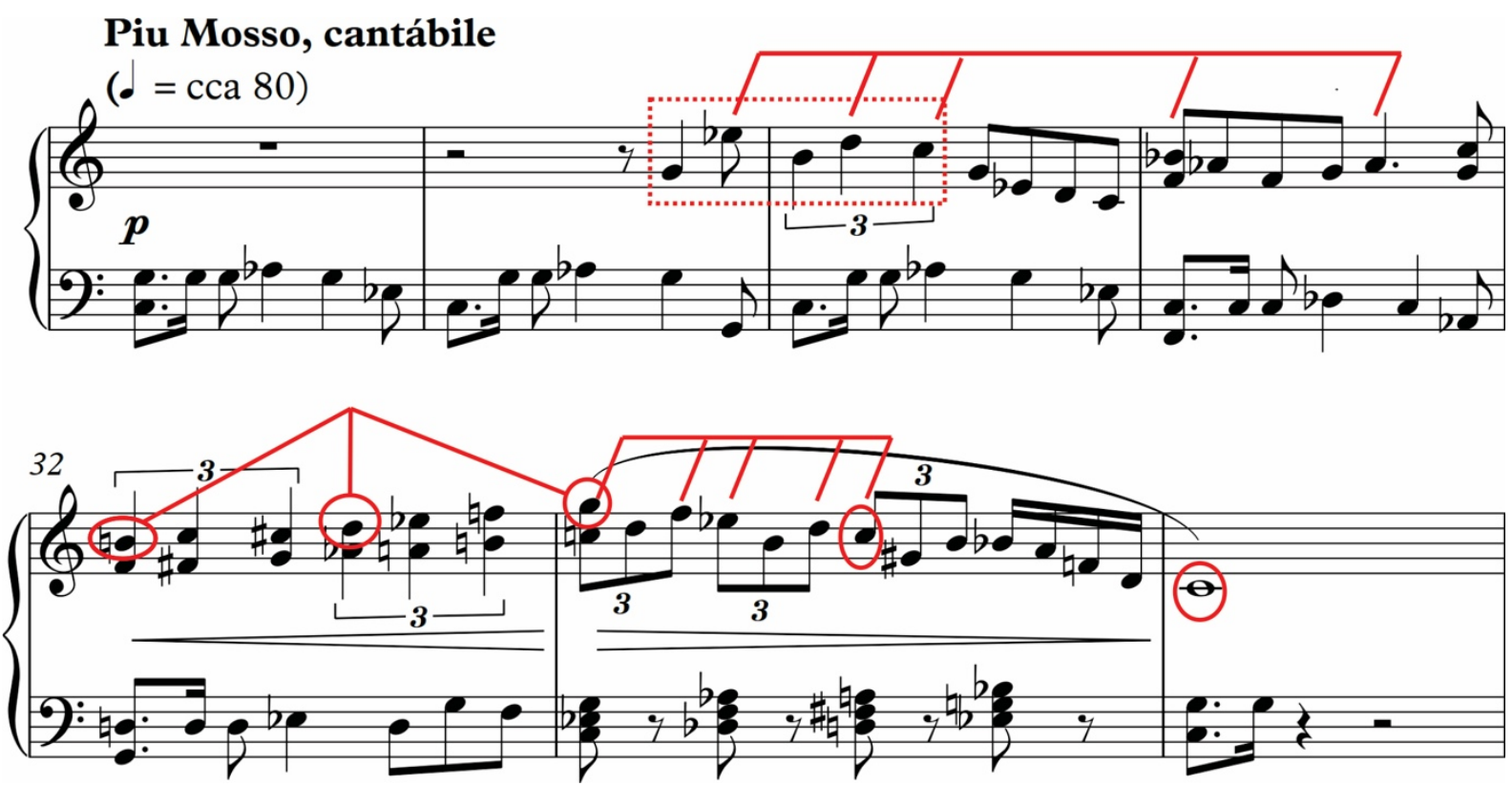

Exemplo 8a: Chacona ao Luar, c. 28-34 (estrutura melódica fundamental)

como o sagrado e o profano, o sério e o cômico, o sublime e o grotesco, o grande e o insignificante, eliminando as distâncias e relativizando as verdades estabelecidas.

${ }^{17} \mathrm{O}$ gesto ondulante que inicia essa melodia - correspondente ao contorno intervalar $[+8,-4,+3,-$ $2,-5]$ - pode ser considerado como característico do inconsciente musical vernáculo brasileiro. 

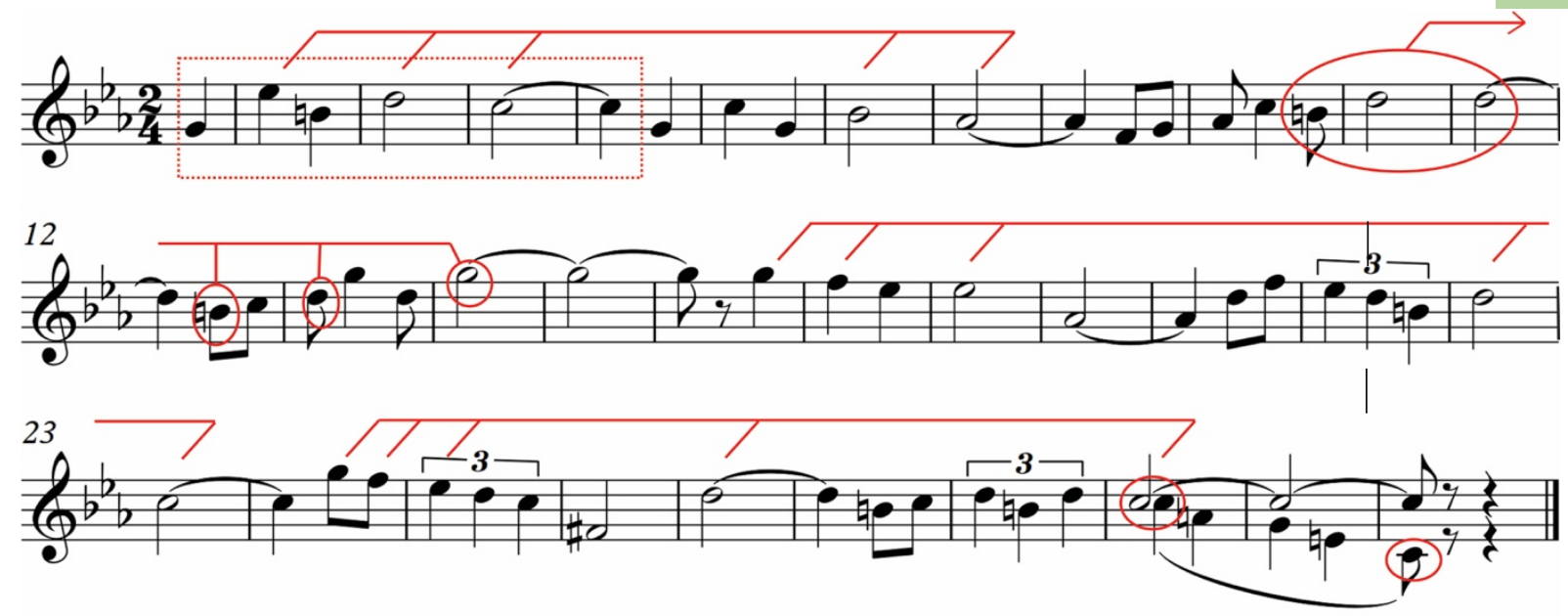

Exemplo 8b: As Pastorinhas (Noel Rosa e Braguinha), c. 1-32 (estrutura melódica fundamental)

$\mathrm{Na}$ frase consequente (Ex. 9), observa-se o ganho em tensão, energia e ímpeto bruscamente interrompido pelo súbito, inesperado reinício da Seção B, novamente inconclusivo.
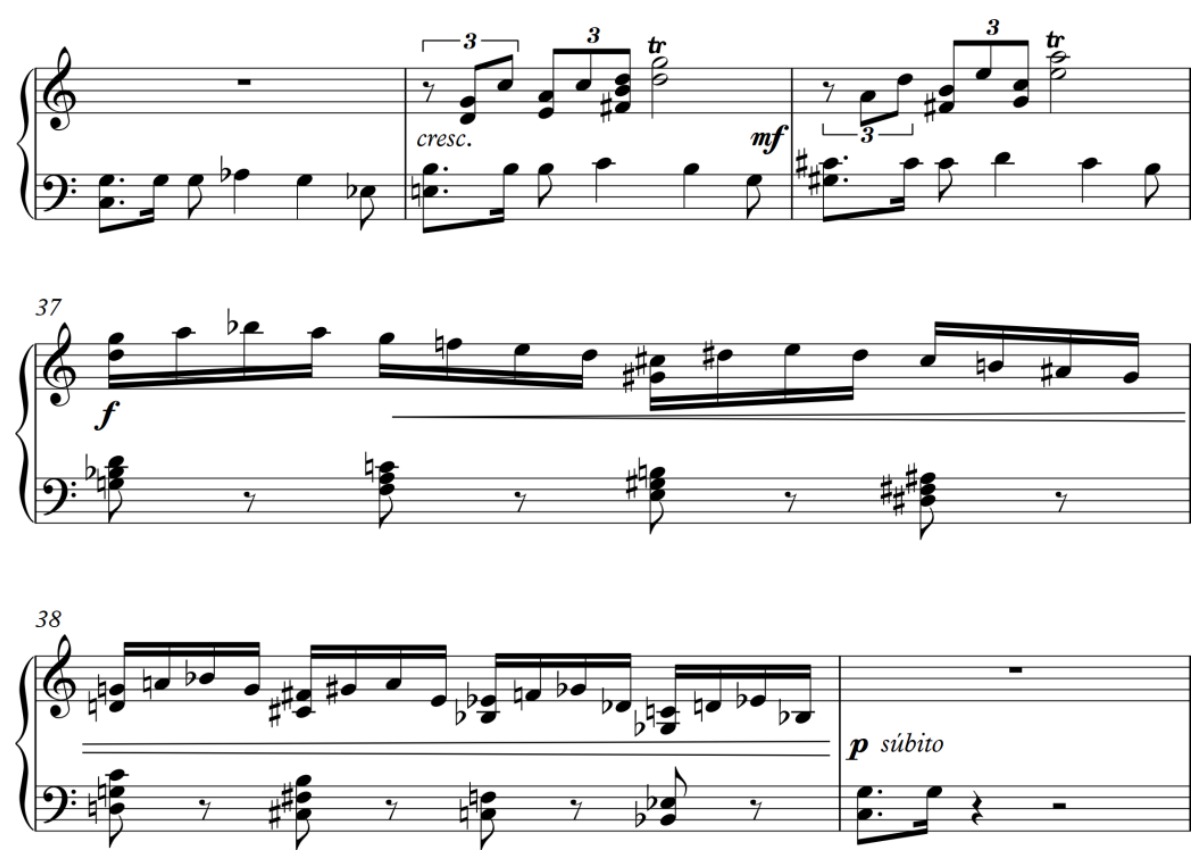

Exemplo 9: Chacona ao Luar, c. 34-39

Considerada em relação à narrativa em progresso, a Seção B foge à realidade. Poderíamos considera-la como um "delírio" da personagem musical? Um surto da imaginação criativa? Ou invocarmos Lacan para encontrar nessa 
evocação carnavalesca o "objeto a" (o objeto causa do desejo, em direção ao qual o sujeito persiste, na ânsia em preencher sua falta primordial)? ${ }^{18}$

Se a expectativa para o que virá após essa espécie de "magia musical" for uma consequência da transvaloração cultural - isto é, o reconhecimento de uma peripeteia ${ }^{19}$ na narrativa -, a música seguinte não a satisfaz. Após a Seção B, o que ocorre é uma repetição da Seção A e da seção transitiva, sem alterações (Ex. $10)$.
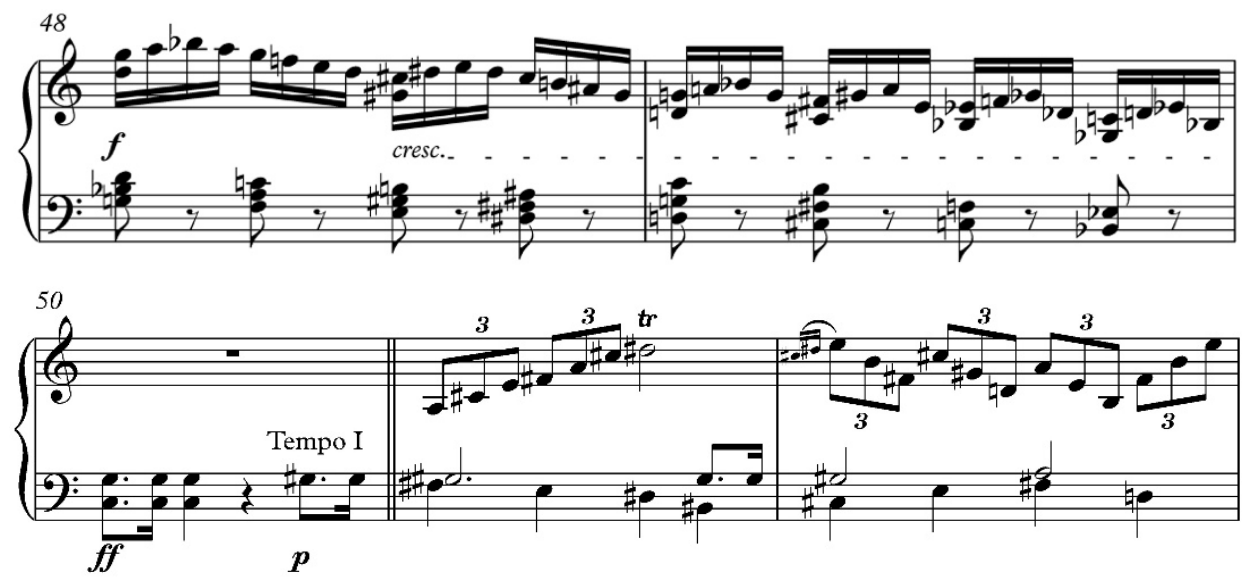

Exemplo 10: Chacona ao Luar, c. 48-52

Uma breve Coda em estilo alla toccata (Ex. 11) finaliza a peça, trazendo à memória a dramática conclusão da Seção A (Ex. 5, c. 18-19). No entanto, se, na finalização da Seção A, a repetição da estrutura acórdica seguida de longas pausas gera tensão e expectativa (uma espécie de propulsão), na conclusão da Coda, diferentemente, o ataque da nota Tônica no registro gravíssimo, em intensidade extrema, após um vertiginoso desabamento da tessitura, traz a sensação de ponto final, de nada mais a dizer.

\footnotetext{
${ }^{18} \mathrm{O}$ "objeto a" é o que perseguimos nas nossas fantasias, sem jamais alcançarmos realmente. É o objeto que constitui e sustenta a fantasia, a qual, por sua vez, é o suporte do desejo; é da fantasia que o desejo se vale nas suas vãs tentativas de satisfação.

19 Peripeteia: reviravolta que caracteriza a narrativa clássica, conduzindo-a a um desfecho catártico.
} 

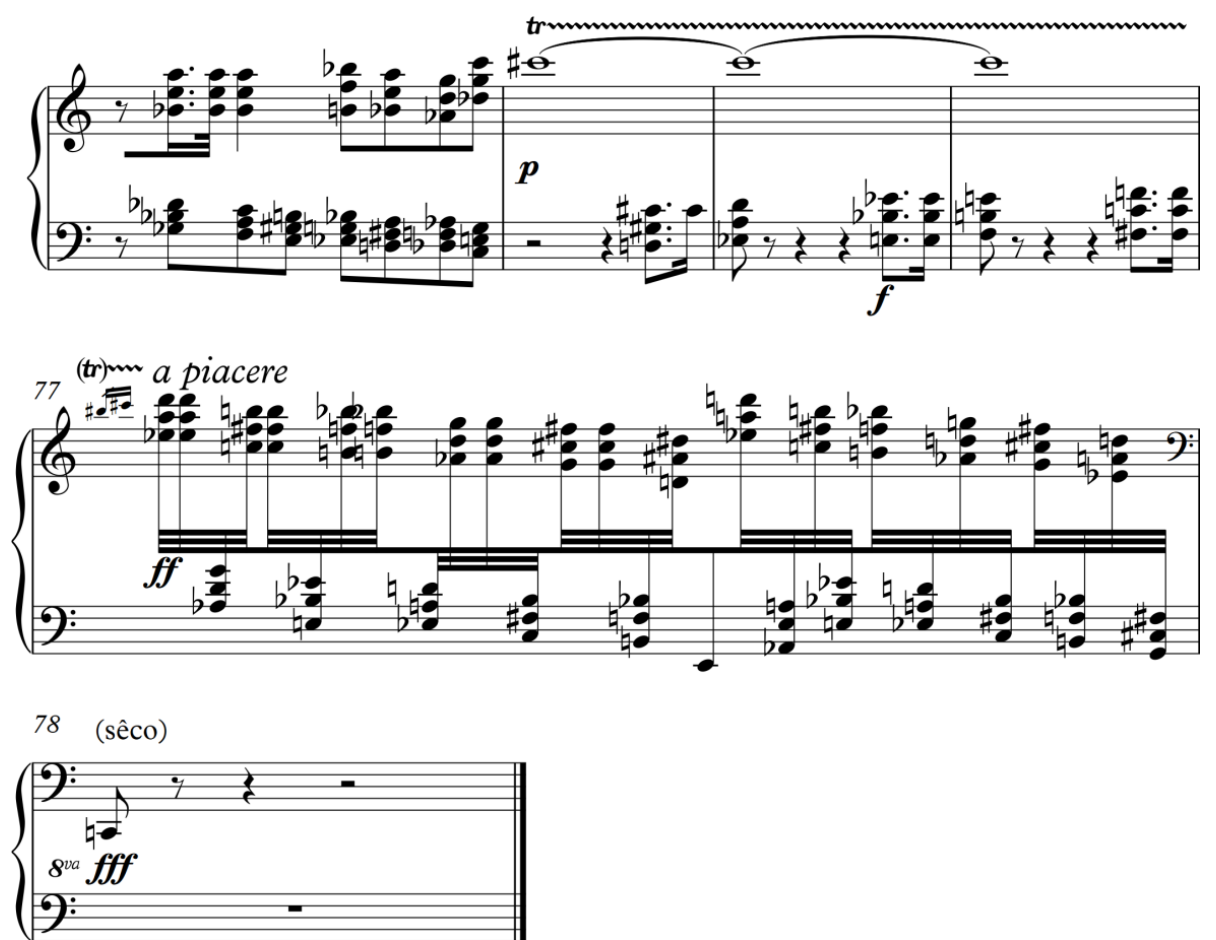

Exemplo 11: Chacona ao Luar, c. 73-78

\section{Hermenêutica narrativa}

Como pudemos observar, a Chacona de Krieger tem uma inquestionável substância narrativa. Ao mesmo tempo, porém, ela apresenta um problema narrativo. A peça se desenvolve numa vertente de sistema tonal expandido, cujo discurso se caracteriza, basicamente, pela causalidade linear, com estruturas de tensão, culminância e relax, conforme o modelo direcional e cumulativo da narrativa clássica. Nesta perspectiva discursiva, a repetição idêntica da Seção A em sequência à Seção B apresenta-se como um enigma: devir sem acúmulo de experiência! Do ponto de vista narrativo, a análise da partitura tropeça no compasso 50. A partir de então, a trama em construção não poderá conduzir-se conforme a expectativa de uma conclusão "coerente" e "decorrente" da Seção B; ou seja, do resultado da confrontação entre uma personagem caracteristicamente apolínea - regida pelo princípio da razão harmoniosa e comedida - e o dionisíaco "outro" - de natureza prazerosa e voluptuosa; esse "outro", que se revela como "o estranho", no sentido freudiano: ${ }^{20} \mathrm{o}$ assustador, que remete ao familiar, ao déjà

20 "O estranho" é uma tradução do conceito freudiano "das Unheimliche", identificado como um assunto da Estética que pertence à categoria "do assustador, do que causa medo e terror" (dass 
vu (a estimulante insinuação da rítmica carnavalesca ao final da Seção A, mostrada no Ex. 5).

O retorno inalterado da Seção A após a Seção B significa, agora para o analista, das Unheimliche: o surpreendente, inesperado regresso ao familiar, causando estranheza. Diante do que se dá a perceber como uma reversão aparentemente ilógica do discurso - uma "dissonância cognitiva"21 -, a atitude do analista é parar, refletir, e admitir que a personagem tem direito a definir sua história; reconhecer que o analista é um mero observador, em vez de "construtor" da trama; e que, como tal, sua tarefa é empenhar-se numa escuta perscrutativa.

Se o tema da narrativa é o sujeito Beethoven, deve-se considerar a complexidade da personagem, cujo problema existencial - o conflito entre a surdez e sua atividade vital e profissional - tem óbvios reflexos sígnicos na sua produção artística tanto quanto na sua interação com a realidade (segundo relatos de época). Por isso, uma interpretação narrativa que pretende referir-se a Beethoven pede por uma hermenêutica multifocal (interdisciplinar), que não minimize o drama existencial.

Quando a busca por auxílio em teorias da literatura e da semiótica não foram suficientes para a decifragem do enigma da reprise, busquei o apoio teórico da psicanálise. ${ }^{22} \mathrm{~A}$ compreensão da interdependência entre as três ordens que compõem a estrutura fundamental da psicanálise lacaniana - o Imaginário (I), o Simbólico (S) e o Real (R) - ajudou-me a encontrar uma solução narrativa para a estrutura da Chaconna. ${ }^{23}$ Entendo que: 1) a Seção A se refere à fase

zum Schreckhaften, Angst- und Grauenerregenden gehört); [...] jene Art des Schreckhaften, welche auf das Altbekannte, Längstvertraute zurückgeht) (Freud [1919] 2012, I, p.1).

${ }^{21}$ Refiro-me à teoria da dissonância cognitiva de Leon Festinger, de acordo com a qual "a relação entre dois elementos é dissonante se [...] um não decorre do outro, ou não se espera que decorra do outro. [...] Se, considerando um par de elementos, qualquer um decorre do outro, então a relação entre eles é consonante" (the relation between two elements is dissonant if [...] the one does not, or would not be expected to, follow from the other. [...] If, considering a pair of elements, either one does follow from the other, then the relation between them is consonant) (Festinger 1956).

${ }^{22}$ Agradeço aos psicólogos Analícea Calmon (Salvador-BA) e Luis Andrade (João Pessoa-PB) a atenciosa supervisão da parte teórica deste estudo, referente ao campo da psicanálise.

${ }^{23}$ Cada uma dessas ordens (ou dimensões) corresponde a um aspecto específico da vida mental do ser humano maduro, nos quais, através dos quais e pelos quais o indivíduo é determinado. $\mathrm{O}$ "nó borromeano" (vide figura abaixo) ilustra a interdependência das três ordens: dois elos separados são unidos por um terceiro de tal forma que, se qualquer deles se desliga, o todo se 
construtiva da imagem da personagem, em gradativo deslocamento para adiante do seu contexto original, na busca da satisfação de uma necessidade intrínseca; 2) a Seção B corresponde à fase de construção do simbólico (o universo do sonho, da fantasia); à desestabilização provisória do Eu submisso à cultura estranha; 3) a reprise da Seção A configura a emergência da dimensão do real, locus da profunda verdade: a falta de sentido; ${ }^{24} 4$ ) a Coda, conduzindo ao trágico final de sensação do "nada mais a dizer", poderia ser compreendida sob o ponto de vista da "pulsão de morte": a tendência ao retorno do que é primordial ao nascimento dos símbolos.

Em outras palavras, a submissão da ansiosa personagem ao estranhamento cultural da Seção B significa um "delírio transitório", entrega ao hedonismo, férias do bom senso, após o que ela volta ao seu mundo dividido entre tradição e invenção, à sua impulsividade dramática, à angustiante busca da originalidade entre ideias inconclusas e recomeços, levando à conclusão de que não há "mais nada a ser". O retorno à Seção A, seguida da seção transitiva que não mais conduz à Seção B e sim à Coda, parece corroborar a suposição de que a Seção B representa o "objeto a" de Lacan; isto é, o objeto causa do desejo, que nunca pode ser alcançado.

Esta perspectiva hermenêutica proveio da escritura da peça; de uma representação simbólica cuja incompletude ontológica demanda a fenomenologia da performance, seu alter ego. A fixidez da escrita, é sabido, desfaz-se na performance. Embora a partitura não apresente nenhuma alteração na reprise da Seção $A$, após a experiência da Seção B é muito provável que o/a “intérprete" não a execute simplesmente como um evento memorizado, mas sob

desmorona; a relação topológica entre eles é o que mantém a estrutura íntegra. Da mesma forma, cada uma das três ordens é fundamental ao todo; a separação de qualquer delas automaticamente resulta no colapso do nexo integral, com resultados catastróficos para o indivíduo.

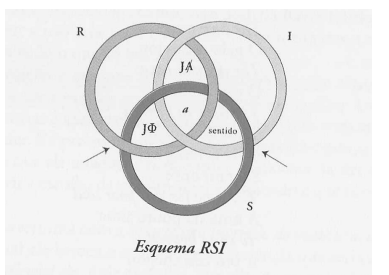

${ }^{24}$ Assim como a batida na porta que interrompe o sonho, o inesperado reinício da peça interrompendo a conclusão da Seção $B$ reconduz a personagem da narrativa à profunda verdade da falta de sentido. 
o efeito da imersão na Seção B; da obra em seu devir. ${ }^{25}$ Também é provável que o ouvinte, por sua vez, escute a reprise interpretada adicionando a memória cumulativa da uma escuta ativa. Possíveis interpretações, portanto, dependem do que se tome como ponto de observação analítica - a partitura (a estrutura muda) ou a performance (a prazerosa "fala" musical).

Concluindo estas reflexões sobre a narratividade implícita na estrutura da Chacona de Krieger de uma forma aberta, ambígua e questionável, cedo a última palavra a Lacan: “Quando se escreve, pode-se muito bem tocar o real, mas não o verdadeiro" (Lacan 2007, p. 78).

\section{Referências}

1. Almén, Byron. 2003. Narrative Archetypes: A Critique, Theory, and Method of Narrative Analysis. Journal of Music Theory, 47/1, p. 1-39.

2. Brooks, Peter. 1984. Repetition, Repression, and Return: The Plotting of Great Expectations. In: Reading for the Plot: Design and Intention in Narrative. New York: Knopf, p. 113-142.

3. Festinger, Leon.1956. An Introduction to the Theory of Cognitive Dissonance. Disponível em: https://www.panarchy.org/festinger/dissonance.html. Acesso em 20 de dezembro de 2018.

4. Freud, Sigmund. [1919] 2012. Das Unheimliche. Bremen: Europäische Literaturverlag $\mathrm{GmbH}$. Disponível em: http://istitutosvizzero.it/wpcontent/uploads/2018/09/ISR_StudioRoma_Freud_DE.pdf. Acesso em 8 de janeiro de 2019.

5. Grabócz, Márta, and Ryan McClelland. 1999. Paul Ricœur's Theories of Narrative and their Relevance for Musical Narrativity. Indiana Theory Review 20/2, p. 19-39.

6. Lacan, Jacques. 2007. O Seminário - livro 23, O sinthoma 1975-1976. Trad. Sérgio Laia. Rio de Janeiro: Zahar.

7. Nogueira, Marcos. 2019. Dimensões da produção imaginativa musical: movimentos, formas e intenções. In: Nogueira, Ilza e Valério Fiel da Costa

${ }^{25}$ Comentando sobre sua visão interpretativa da Chacona, a pianista Cristina Gerling afirmou idealizar a execução da Seção A e da sua reprise distinguindo-as pela valorização dos traços culturais que se entrecruzam. Na primeira vez, o comedido contraponto da mão esquerda (reminiscência da tradição clássica eurocêntrica) seria evidenciado em primeiro plano, enquanto na segunda vez o extravagante lirismo da melodia executada pela mão direita (insinuando o pontilhismo idiomático das cordas dedilhadas) estaria proeminente. 
MUSICA THEORICA Revista da Associação Brasileira de Teoria e Análise Musical 2019, v. 4, n. 1, p. 11-29 - Journal of the Brazilian Society for Music Theory and Analysis@ TeMA 2019 - ISSN 2525-5541

(eds.). A Experiência musical: perspectivas teóricas. Série Congressos da TeMA 3, Salvador: UFBA, p. 17-35.

8. Rogers, Robert. 1987. Freud and the Semiotics of Repetition. Poetics Today, 8:3/4, p. 579-590. 